\title{
Field study of the long-term release of block copolymers from fouling-release coatings
}

\author{
Noguer, Albert Camós; Olsen, A.; Hvilsted, Søren; Kiil, Søren
}

Published in:

Progress in Organic Coatings

Link to article, DOI:

10.1016/j.porgcoat.2017.07.001

Publication date:

2017

Document Version

Peer reviewed version

Link back to DTU Orbit

Citation $(A P A)$ :

Noguer, A. C., Olsen, A., Hvilsted, S., \& Kiil, S. (2017). Field study of the long-term release of block copolymers from fouling-release coatings. Progress in Organic Coatings, 112, 101-108.

https://doi.org/10.1016/j.porgcoat.2017.07.001

\section{General rights}

Copyright and moral rights for the publications made accessible in the public portal are retained by the authors and/or other copyright owners and it is a condition of accessing publications that users recognise and abide by the legal requirements associated with these rights.

- Users may download and print one copy of any publication from the public portal for the purpose of private study or research.

- You may not further distribute the material or use it for any profit-making activity or commercial gain

- You may freely distribute the URL identifying the publication in the public portal 


\title{
Field study of the long-term release of block copolymers from fouling-release coatings
}

\author{
A. Camós Noguer ${ }^{\mathrm{a}, \mathrm{b}}$, S. M. Olsen ${ }^{\mathrm{b}}$, S. Hvilsted ${ }^{\mathrm{a}}$, S. Kiil ${ }^{\mathrm{a}, *}$ \\ a \\ Department of Chemical and Biochemical Engineering, Technical University of Denmark (DTU), \\ Building 229, 2800 Kgs. Lyngby, Denmark \\ email: alno@kt.dtu.dk \\ telephone: +4545252829 \\ b \\ Department of Fouling Release Systems, Hempel A/S, Lundtoftegårdsvej 91, 2800 Kgs. Lyngby, \\ Denmark \\ email: stmo@hempel.com \\ telephone: +4545933800
}

*Corresponding author, e-mail adress: sk@kt.dtu.dk, telephone: +45 45252827 (Søren Kiil)

\begin{abstract}
The addition of block copolymers (i.e. oils) is a common technique to enhance the biofoulingresistance properties of poly(dimethylsiloxane) (PDMS)-based fouling-release coatings. These copolymers diffuse from the bulk to the surface of the coating, thus modifying the properties of the surface and providing fouling-resistance properties. Upon release, dissolution or degradation of copolymer molecules at the surface, new molecules can diffuse from the bulk of the coating and cover the surface. Therefore, the long-term performance of these coatings is dependent on the stability and release rate of copolymer molecules from the surface.
\end{abstract}

A method was developed to quantify the concentration of PDMS-based block copolymers from foulingrelease coatings. About 300 experimental coatings exposed to seawater for up to 5.2 years were included in the analysis. The results showed that the loss of copolymer (in \% on a weight basis) is significantly higher in warm waters, while the initial copolymer concentration in the coating does not have any effect for copolymer concentrations between 1 and $7 \mathrm{wt} \%$. In short-term exposure, it was found that loss of copolymer was much higher in coatings containing small amounts of an organic biocide (copper pyrithione). Conversely, biocide-containing coatings displayed larger copolymer retention values in long-term experiments. Opposite results were obtained for biocide-free coatings, suggesting that the addition of the organic biocide alters the release profile of copolymers from fouling- 
release coatings. Finally, the potential of long-term field-studies is discussed, as compared to shortterm laboratory experiments usually performed within fouling-release coatings studies.

\section{Highlights}

A method to assess the concentration of copolymers in coatings is developed.

Loss of copolymer is strongly affected by seawater temperature and addition of biocide.

Loss of copolymer is not dependent on the initial copolymer concentration.

Different release profiles depending on the addition of an organic biocide are shown.

\section{Keywords}

Fouling-release coatings, block copolymers, oils, release

\section{Introduction}

After the ban of tributyltin self-polishing copolymer (TBT-SPC) coatings was approved by the International Maritime Organization (IMO) in 1998 [1], the coatings industry focused on developing environmentally-friendly biocide-free coatings [2,3]. Hydrophobic polydimethylsiloxane (PDMS)-based coatings, usually known as fouling-release coatings (FRC), emerged as a solution due to its unique fouling-release properties. These have been attributed to its low critical surface energy $\left(\gamma_{c}\right)[4]$, low elastic modulus $(E)$ [5], low glass transition temperature $\left(T_{g}\right)[6]$ and smooth surface [7] and result in weak adhesion between the adhesives secreted by biofoulants and the surface of the coating [8-10]. Consequently, the biofouling film is detached (i.e. released) when the vessel navigates at moderate speeds (about 15 knots) [11]. However, its hydrophobic surface favours the adhesion of some marine organisms, which cannot always be completely removed by hydrodynamic forces. It has been shown, for example, that diatoms cannot be released at speeds as high as 30 knots [3].

To improve the biofouling-release properties of FRC, "oils" (mostly polysiloxane-based fluid additives) have been traditionally added [3,8]. These oils consist of block copolymers containing different chemical moieties. The mostly employed polymers have been fluorinated- and polyether-based polymers, as well as phenyl-modified polysiloxanes [3]. For example, poly(tetrafluoroethylene) (PTFE) and poly(ethylene glycol) (PEG) have been extensively used. In addition, it has been shown that copolymers based on other polymers [12], zwitterions [13] or peptides [14] can also provide nonfouling properties when added as additives to different coatings. The effect of the chemistry and structure of various oils on the adhesion strength of different biofouling species have been studied. The results show that the adhesion strength reduction is highly dependent on the chemistry of the used oil as well as the biofouling organism investigated $[12,15]$.

These oils segregate from the bulk and cover the surface of the coatings upon immersion $[16,17]$. On the surface of the coatings, one of the copolymer blocks acts as an anchor to the surface and imparts stability to the copolymer molecule $[18,19]$. The other block(s) of the copolymer is usually extended to 
seawater (sometimes in the form of a polymer brush) and confers non-fouling (i.e. repellence) properties [18]. Consequently, the addition of small amounts of these additives result in the modification of the physicochemical properties of the surface with a very small influence on the bulk properties of the coating $[12,20,21]$.

Nonetheless, it has been suggested that these oils can be "washed away" (i.e. released or dissolved in seawater) and/or degraded at the surface of the coating. When a molecule from the surface of the coating is removed, a new molecule diffuse from the bulk of the coating to cover the surface [20]. This "self-healing" process can take place as long as copolymer molecules are available in the bulk of the coating. The properties of these coatings are hence expected to deteriorate upon shortage of copolymer molecules in the bulk. The anchoring capabilities of this kind of surface-active copolymers on different polymeric matrices have been studied. In these investigations, different surfactants and block copolymers have been added to PDMS (or other polymeric matrices) and the wettability of the surface has been studied after soaking the samples in water for different exposure times [22-27]. For example, Seo and Lee [22] added a surfactant based on poly(ethylene glycol) (PEG) to PDMS. After immersion in water for 18 days, significant changes in wettability of the PDMS surface were observed and attributed to additive depletion. Similarly, a PDMS-PEG-based copolymer was added to PDMS by Kim et al. [23] and samples of the material were soaked in water for 35 days. Slight differences on the surface of the PDMS samples after exposure were also reported. Madadi and Casals-Terré [26] could see significant differences in hydrophilicity in PDMS samples modified with non-ionic surfactants, when the samples were exposed to contact with water for short periods. Finally, Fatona et al. [27] analysed PEG-based surfactants and copolymers with different hydrophobic groups added to PDMS elastomers and soaked for 20 hours in water. They showed that the stability of these additives on the PDMS surface was significantly higher when copolymers containing a PDMS block were used, compared to those containing an alkyl hydrophobic group. Nonetheless, the exposure times investigated in the aforementioned studies are not representative for fouling-release coatings, which are exposed to seawater over several years. Hence, the usefulness of such experiments on the studied coatings is limited. Recently, some novel PDMS-based coatings containing both the traditional "oils" and biocides have been commercialized. The addition of small amounts of biocides is suggested to improve the non-fouling properties of the coatings (specially in idle conditions). The use of organic biocides such as zinc pyrithione, Zineb and Irgarol together with fouling-release "oils" has been described in different patents $[28,29]$. However, the addition of biocides could significantly influence the behaviour and release of these copolymers, both due to the presence of biocide in the film and the leached layer that is generated upon its dissolution.

It is well recognized that addition of block copolymers (i.e. oils) to fouling-release coatings enhances the fouling-resistance of these coatings to a great extent. Therefore, being able to quantify and control the processes that dictate the release rate at the surface of the coating is crucial for the development of robust long-lasting coatings. With the aim of better understanding the stability of polymeric-based additives in silicone coatings, up to 300 experimental fouling-release coatings exposed to seawater for different periods of time have been analysed. The experimental coatings consist mainly of a PDMS 
binder and a surface-active additive, a PDMS-PEG-based copolymer. First, a method to quantify the amount of additive present in coatings has been developed inspired by the work of Reynier et al. [30]. Then, the experimental fouling-release coatings, exposed to seawater for different times have been analysed and compared to coatings exposed in a laboratory rotor in controlled conditions. The influence of different variables/parameters on the release of these copolymers has been studied. These variables include: (1) temperature of seawater, (2) the chemistry of the crosslinker, (3) the molecular weight $\left(\mathrm{M}_{\mathrm{w}}\right)$ of the copolymer and the initial concentration of (4) biocide and (5) copolymer in the coating. Finally, the influence of the aforementioned variables on the release/loss of copolymer from PDMS-coatings is discussed. The conclusions drawn from this long-term field-study possess the advantage of relying on results obtained from coatings immersed in real seawater conditions, in comparison to traditional short-term laboratory experiments. These results obtained provide some insights and findings, which might not be available when short-term experiments in ideal conditions are employed.

\section{Materials and Methods}

\subsection{Materials}

Di-hydroxy terminated polydimethylsiloxane (4000 cSt) was purchased from Dow Corning. Vinyl tris(methyl ethyl ketoxime) silane (crosslinker I), a pre-polymerized ethoxysilane crosslinker (crosslinker II), and a methoxy functional vinyl siloxane oligomer (crosslinker III) were purchased from Evonik Industries and can be seen in Table 1. Surface-treated fumed silica $\left(\mathrm{SiO}_{2}\right.$, average particle size about $15 \mathrm{~nm}$ ) was also received from Evonik and red iron oxide $\left(\mathrm{Fe}_{2} \mathrm{O}_{3}\right)$ pigment Bayferrox 130M from Lanxess. Two different PDMS-PEG-based block copolymers (copolymer A and copolymer B) were obtained from different suppliers with $M_{w}=1.000-10.000 \mathrm{~g} / \mathrm{mol}$ and triblock $A B A$ structure. The molecular weight of copolymer A was $\sim 75 \%$ larger than of copolymer B. Copper pyrithione (CuPT), also known as copper omadine, was obtained from Lonza.

Table 1. Chemical structures of the three crosslinkers investigated.

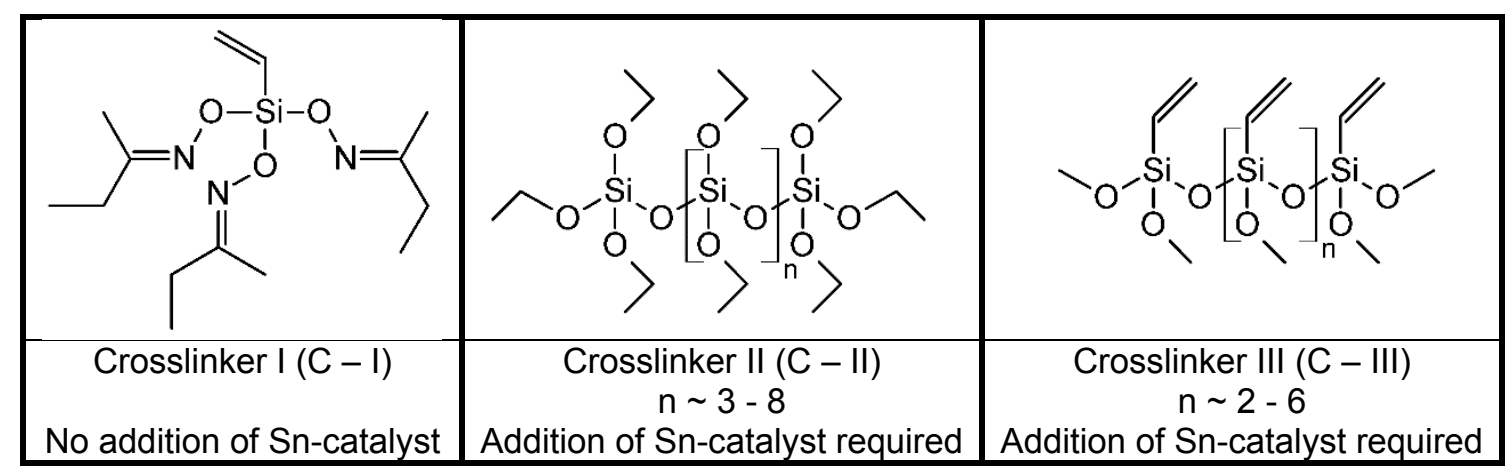

\subsection{Formulation of coatings}

The coatings were prepared by mixing three components: (1) base (containing binder, solvent, silica, pigment and CuPT), (2) crosslinker (I, II or III) and (3) a PDMS-PEG-based copolymer (A or B). The base was prepared by mixing silanol-terminated PDMS with xylene (about $15 \mathrm{wt} \%$ ) and with a series 
of components. Iron oxide $\left(\mathrm{Fe}_{2} \mathrm{O}_{3}\right)$ and fumed silica $\left(\mathrm{SiO}_{2}\right)$ were added so they accounted for $5 \%$ and $1 \%$ of the dry weight of the film respectively. The organic biocide was added in different amounts, so it accounted from 0 to $7 \%$ of the dry weight of the film. The base was mixed in a pearl mill at approximately $3000 \mathrm{rpm}$ for 30 minutes. Then, base, crosslinker and copolymer were mixed by handmixing at room temperature and applied. A small amount of tin-based catalyst was added to compositions with crosslinkers II and III to compensate for the lower reactivity of these crosslinking agents.

\subsection{Preparation of coatings}

Poly(methyl methacrylate) (PMMA) substrates $(10 \times 20 \mathrm{~cm}$ ) were spray-coated with a $300 \mu \mathrm{m}$ (wet thickness) layer of a tiecoat mainly consisting of poly(vinyl chloride)-co-poly(vinyl isobutyl ether) and cured at room temperature for 48 hours. The tiecoat was aimed at providing adhesion between the PDMS coating and the substrate. Then, the PDMS-based mixtures were applied on the coated panels using an 8-cm doctor blade applicator with a $400 \mu \mathrm{m}$ gap and cured for a week at room temperature. These coatings were used for static immersion tests in seawater. A similar procedure was used to apply coatings for rotary experiments on poly(ethylene terephthalate) (PET) foils.

\subsection{Exposure of coatings}

\subsubsection{Static exposure}

The coatings applied on PMMA substrates were immersed in static conditions in seawater in

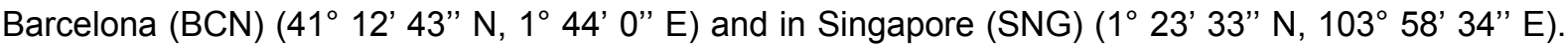
Coatings were retrieved from the exposure sites and analysed after different exposure times. Significant differences in seawater temperature exist between the two locations. While seawater temperature is relatively constant throughout the year in Singapore $\left(27-30^{\circ} \mathrm{C}\right)$, in Barcelona it can fluctuate between $13^{\circ} \mathrm{C}$ and $25^{\circ} \mathrm{C}$ depending on the season. Note that other differences might exist between the two exposure sites regarding salinity, oxygen concentration, organic matter and local current speeds among others, though these are expected to have a limited effect on the release of the investigated copolymers. This, however, should be further studied for confirmation.

All the coatings exposed to seawater in Barcelona and Singapore were applied by the same person in the same laboratory, and then sent to the immersion sites. Thereby, any differences in copolymer loss between the exposure sites cannot be ascribed to coating composition or application differences.

\subsubsection{Rotary exposure}

The coated PET films were cut in strips of $2.5 \mathrm{~cm}$ and mounted on the laboratory rotor. The rotor operated in artificial seawater at $25^{\circ} \mathrm{C}$ rotating at $20 \mathrm{knots}$. The $\mathrm{pH}$ was maintained at 8.2 by addition of sodium hydroxide and hydrochloric acid. A detailed description of the rotor structure and properties can be found elsewhere [31]. Samples were retrieved at different exposure times for analysis.

\subsection{Determination of copolymer concentration in PDMS-based coatings}

Size exclusion chromatography (SEC) was used to assess the concentration of copolymer in PDMS coatings. The SEC system consisted of three different columns, an Agilent PLgel Mixed-C $(7.5 \times 300$ $\mathrm{mm}$ ) followed by two Agilent PLgel Mixed-D $(7.5 \times 300 \mathrm{~mm}$ ) columns. An ELS (Evaporative Light 
Scattering) detector was employed. Tetrahydrofuran (THF) was used as eluent at a flow rate of 1 $\mathrm{mL} / \mathrm{min}$ at $22^{\circ} \mathrm{C}$.

A method has been developed to measure the copolymer concentration in coatings, which can be used for both freshly applied coatings, as well as those that have been immersed in seawater. Briefly, the coating analysed is immersed in THF in a closed glass container, where the non-crosslinked molecules and additives, including the studied copolymer, are extracted from the PDMS matrix by the solvent. Then, the THF phase is filtered and run through the SEC system, where the concentration of copolymer is estimated. The steps can be summarized as follows:

1) The PDMS coating is "detached" from the substrate by use of a scalpel, ensuring that no coating remains on the substrate and that no tiecoat is removed.

2) The coating obtained from (1) is immersed in a THF solution for 2 hours under stirring. The THF solvent contains a small amount of low polydispersity-index polystyrene (PS), which is later used as internal standard for quantification purposes.

3) The THF phase is separated and filtered (filter pore size $=20 \mu \mathrm{m}$ ) and run through the SEC system.

4) The area corresponding to the copolymer peak in the chromatogram obtained is measured, as well as the area corresponding to the PS peak (see Figure 1).

5) The measured area for the copolymer is corrected after the area of the PS peak and the amount of coating and THF used. This "corrected area" is proportional to the concentration of copolymer in the coating.

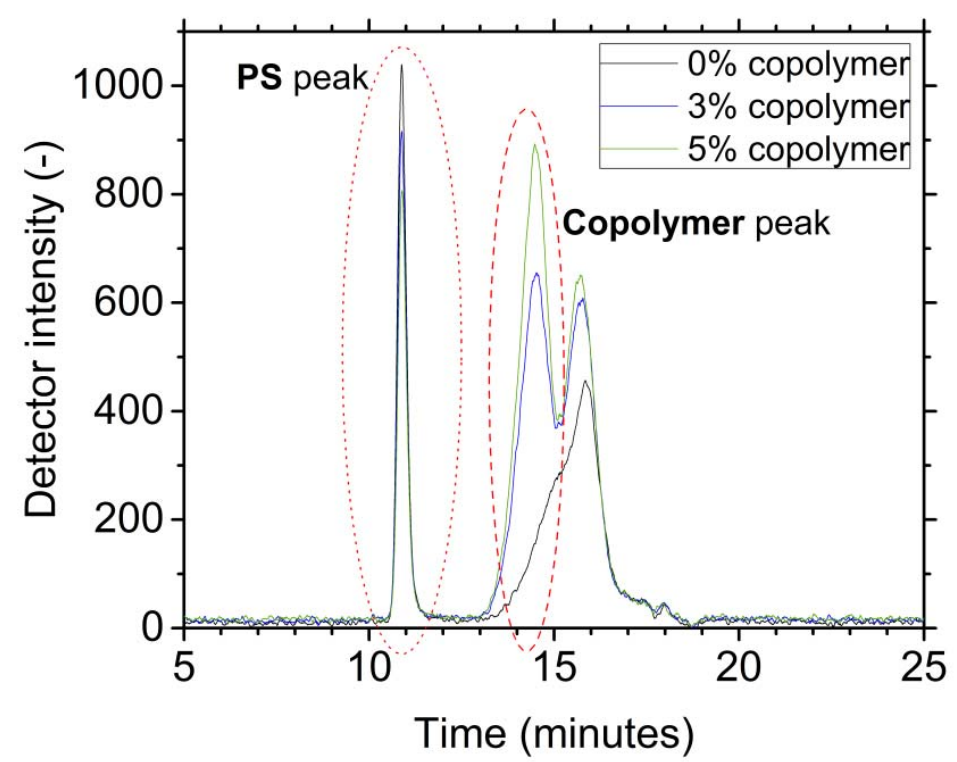

Figure 1. Chromatograms obtained after analysing coatings with three different copolymer concentrations ( $0 \mathrm{wt} \%, 3 \mathrm{wt} \%$ and $5 \mathrm{wt} \%$ ). A red circle has been used to highlight the peaks corresponding to the PS standard $(\cdots)$ and the copolymer (---). 
A series of coatings with different (well-known) copolymer concentrations were prepared, applied on PMMA substrates and cured for a week. The coatings were then analysed using the procedure described above. The "corrected area" obtained from the SEC system was plotted against the concentration of copolymer for each coating, showing a clear correlation between both variables $\left(R^{2}=0.98\right)$ as shown in Figure 2. The calibration curve in Figure 2 has been used to determine the concentration of copolymer in the analysed coatings.

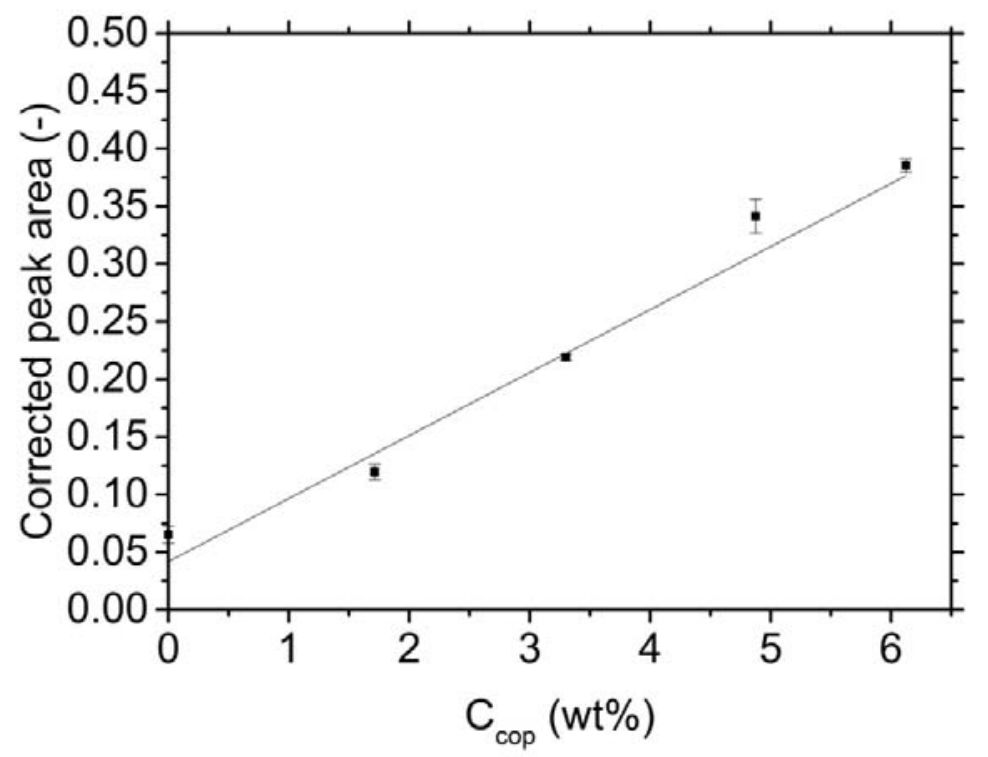

Figure 2. Calibration curve for copolymer A, where the corrected area obtained from the SEC analysis of 5 different coatings is plotted against the copolymer concentration. Three independent measurements were undertaken for each point, and the error bars show the standard deviation.

It has been assumed that the silica $\left(\mathrm{SiO}_{2}\right)$ and pigment $\left(\mathrm{Fe}_{2} \mathrm{O}_{3}\right)$ particles do not leach from the coating upon exposure to seawater. Likewise, non-crosslinked PDMS-chains originating from the incomplete crosslinking of the binder are also assumed to remain in the film throughout the immersion period due to their hydrophobic character.

\subsection{Copolymer concentration and loss in PDMS-based coatings}

The concentration of copolymer is defined as the weight of copolymer found in 1 gram of dry coating, assuming that it is homogeneously distributed. It is expressed in weight percentage as shown in Equation 1. The concentration of CuPT is defined likewise. Unless otherwise stated, all biocide and copolymer concentrations are expressed in wt\%.

$$
C_{\text {cop }}(w t \%)=\frac{m_{\text {cop }}}{m_{\text {coating }}} \cdot 100
$$

(Equation 1)

where $\mathrm{C}_{\text {cop }}$ refers to the copolymer concentration in the coating, $\mathrm{m}_{\text {cop }}$ is the mass of copolymer in $\mathrm{g}$ and $\mathrm{m}_{\text {coating }}$ is the final dry weight of the coating in $\mathrm{g}$. 
The copolymer loss is then defined by Equation 2 .

$$
\text { Copolymer loss }(\%)=\frac{C_{\text {cop }}(t 0)-C_{\text {cop }}(t)}{C_{\text {cop }}(t 0)} \cdot 100
$$

(Equation 2)

where $\mathrm{C}_{\text {cop }}$ refers to the copolymer concentration in the coating and to and $t$ refer respectively to the unexposed and exposed coatings.

\subsection{Uncertainty assessment}

The coatings analysed in this field study do not belong to a unique set of experiments designed to investigation purposes. Instead, the results shown pertain to different groups of experiments conceived to analyse the effect of various parameters. Therefore, slight differences in composition might exist between coatings. Furthermore, the copolymer loss values reported originate from a single measurement, as no replicates were available in most of the cases. Thus, different strategies have been used to overcome these limitations.

First, the different coatings analysed do not present the same precise composition. The particle size, composition and concentration of some constituents (e.g. silica and pigments) vary slightly among formulations. However, coatings with similar formulations have been chosen for analysis and are referred to as "comparable" compositions. Conversely, those with large differences have been disregarded. Examples of comparable compositions include: (1) coatings with the same chemical composition, where the silica $\left(\mathrm{SiO}_{2}\right)$ filler has different particle size (12 $\mu \mathrm{m}$ vs $\left.15 \mu \mathrm{m}\right)$, (2) coatings where the loading of iron oxide $\left(\mathrm{Fe}_{2} \mathrm{O}_{3}\right)$ pigment differs slightly (4.5 wt\% vs $\left.5 \mathrm{wt} \%\right)$ and (3) coatings where the solvent concentration in the base is different (13 wt\% vs $15 \mathrm{wt} \%$ ). In addition, the coatings have been prepared by different people and exposed to seawater at different times (both seasonally and yearly). The uncertainty related to the abovementioned issues cannot be quantified, but is expected to be limited.

To account for the experimental error for each individual measurement, the series of coatings analysed in Figure 2 have been employed. It has been assumed that these samples are representative for all the coatings studied due to their different composition in terms of copolymer concentration. Hence, the average standard deviation of these 5 samples has been calculated and assumed representative for all the analysed coatings. Consequently, the copolymer concentrations estimated in this paper are subject to an uncertainty of $\pm 0.13 \mathrm{wt} \%$. To calculate the standard deviation of the copolymer loss (obtained through Equation 2), "propagation of error" theory has been employed, as detailed elsewhere [32].

\section{Results and Discussion}

Almost 300 experimental coatings with different compositions have been retrieved from the exposure sites in Barcelona and Singapore at different exposure times (up to 5.2 years) and analysed as previously explained. 
a)

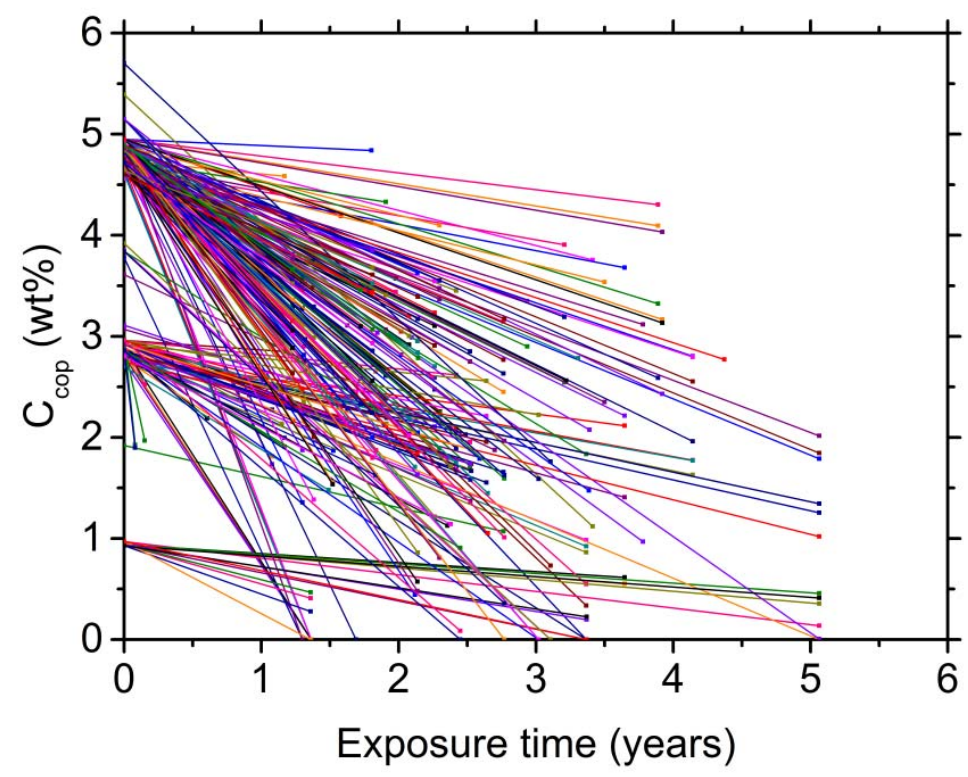

b)

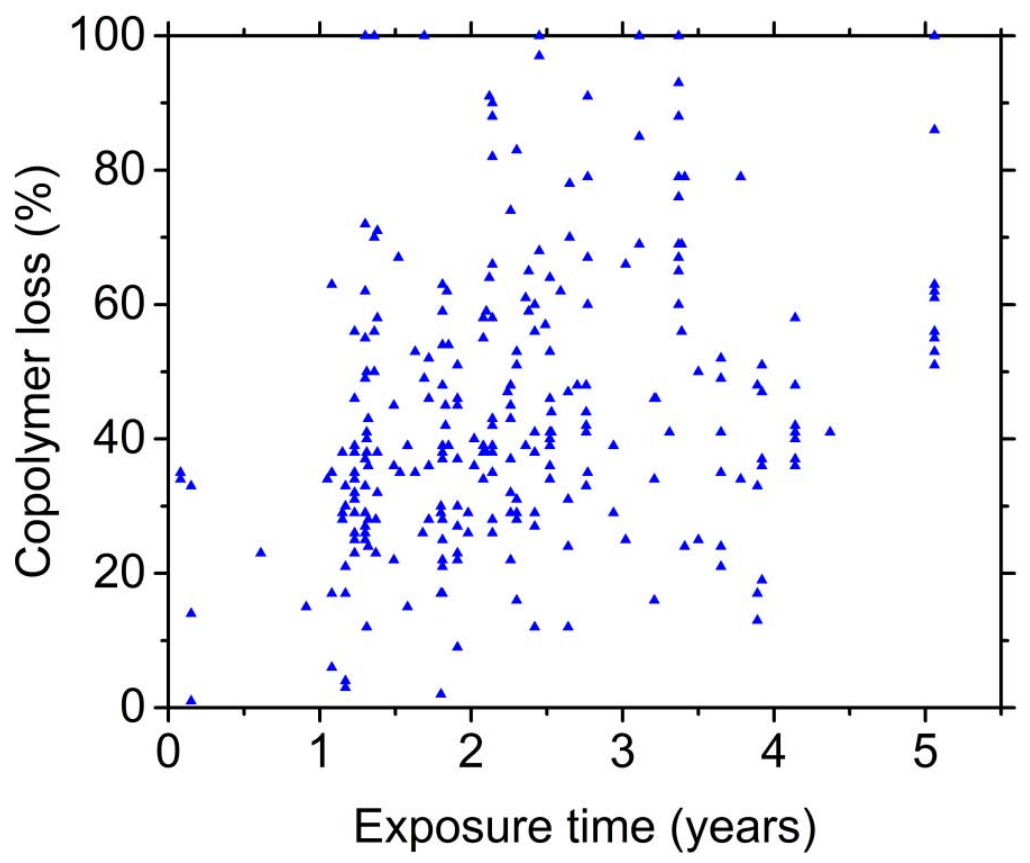

Figure 3. Copolymer concentration (a) and loss (b) for approximately 300 experimental coatings exposed to seawater in Singapore and Barcelona. Large differences in composition exist between the analysed coatings.

Figure $3 a$ shows the initial and final concentration of copolymer in all the analysed coatings. Figure $3 b$ shows the copolymer loss (in \%) for the same coatings. A significant scatter in the results can be clearly seen, probably due to: (1) differences in composition (including fillers, pigments, copolymer and CuPT), (2) exposure to two different locations with different seawater temperatures and (3) different starting immersion dates, among others. Therefore, specific coatings from Figure 3 with comparable compositions and exposure conditions have been selected and compared to coatings exposed in well- 
controlled conditions in the laboratory rotor. Details with the different experimental coatings analysed in this study are provided in Table 2.

Table 2. Series of coatings analysed. Details regarding the exposure site (ROT (laboratory rotor), BCN (Barcelona) and SNG (Singapore)), initial biocide (CuPT) and copolymer concentration (wt\%), exposure time (years) and parameters investigated for each series are provided.

\begin{tabular}{|c|c|c|c|c|c|c|c|c|c|c|c|c|c|c|c|c|c|}
\hline \multirow[t]{2}{*}{ Series } & \multirow{2}{*}{\multicolumn{3}{|c|}{\begin{tabular}{|c|c|c|}
\multicolumn{2}{|c|}{$\begin{array}{c}\text { Exposure } \\
\text { site }\end{array}$} \\
ROT & BCN & SNG \\
\end{tabular}}} & \multicolumn{6}{|c|}{$\begin{array}{c}\text { Initial copolymer } \\
\text { concentration (wt\%) }\end{array}$} & \multicolumn{6}{|c|}{$\begin{array}{c}\text { Initial biocide } \\
\text { concentration (wt\%) }\end{array}$} & \multirow[t]{2}{*}{$\begin{array}{l}\text { Exposure } \\
\text { time (years) }\end{array}$} & \multirow[t]{2}{*}{$\begin{array}{l}\text { Parameters } \\
\text { investigated }\end{array}$} \\
\hline & & & & $1 \%$ & \begin{tabular}{|l|}
$2 \%$ \\
\end{tabular} & $3 \%$ & $5 \%$ & $6 \%$ & $7 \%$ & $0 \%$ & \begin{tabular}{|l|}
$0.5 \%$ \\
\end{tabular} & \begin{tabular}{|l|}
$1 \%$ \\
\end{tabular} & $3 \%$ & $5 \%$ & $7 \%$ & & \\
\hline $\begin{array}{c}\text { A } \\
\text { Fig. } 4\end{array}$ & $x$ & & & & & & $x$ & & & $x$ & & & & & $\mathrm{x}$ & $\begin{array}{c}1 \\
\text { Short-term }\end{array}$ & $\begin{array}{l}\text { Biocide conc. } \\
\text { Copolymer } \mathrm{M}_{\mathrm{w}} \\
\text { Crosslinker }\end{array}$ \\
\hline $\begin{array}{c}\text { B } \\
\text { Fig. } 5\end{array}$ & $x$ & & & & $\mathrm{x}$ & & & $x$ & & $x$ & & & $x$ & & $\mathrm{x}$ & $\begin{array}{c}1 \\
\text { Short-term }\end{array}$ & $\begin{array}{l}\text { Copolymer conc. } \\
\text { Biocide conc. }\end{array}$ \\
\hline $\begin{array}{c}\text { C } \\
\text { Fig. } 6\end{array}$ & & $x$ & $\mathrm{x}$ & & & & $x$ & & $x$ & & $x$ & $\mathrm{x}$ & $x$ & $x$ & $x$ & $\begin{array}{c}2 \\
\text { Mid-term }\end{array}$ & $\begin{array}{c}\text { Copolymer conc. } \\
\text { Biocide conc. } \\
\text { Seawater } \mathrm{T}\end{array}$ \\
\hline $\begin{array}{l}\text { D } \\
\text { Fig. } 7\end{array}$ & & $x$ & $x$ & $x$ & & $x$ & $x$ & & & $x$ & & & $x$ & $x$ & $\mathrm{x}$ & $\begin{array}{c}\text { 3,4 / 5,2 } \\
\text { Long-term }\end{array}$ & $\begin{array}{c}\text { Copolymer conc. } \\
\text { Biocide conc. } \\
\text { Seawater T }\end{array}$ \\
\hline $\begin{array}{c}\text { E } \\
\text { Fig. } 8\end{array}$ & & & $x$ & & & & $x$ & & & & & & & & $\mathrm{x}$ & $\begin{array}{c}0-3,7 \\
\text { Long-term }\end{array}$ & $\begin{array}{c}\text { Time } \\
\text { Seawater T }\end{array}$ \\
\hline $\begin{array}{c}\text { F } \\
\text { Fig. } 9\end{array}$ & $x$ & & & & & & $x$ & & & $x$ & & & & & $\mathrm{x}$ & $\begin{array}{c}0-1 \\
\text { Short-term }\end{array}$ & $\begin{array}{c}\text { Time } \\
\text { Biocide conc. }\end{array}$ \\
\hline
\end{tabular}

\subsection{Laboratory rotary experiments}

Coatings with different formulations were exposed in the laboratory rotor for 1 year to study the effect of the following variables on the loss of copolymer from fouling-release coatings:

1) The $M_{w}$ of the PDMS-PEG-based copolymer used.

2) The crosslinker chosen to cure the PDMS binder.

3) The initial concentration of copolymer in the coating.

4) The initial concentration of biocide in the coating.

The results can be seen in Figures 4 and 5. Figure 4 shows the loss of copolymer for eight different coatings initially containing 5 wt\% copolymer (series A in Table 2). In these series, different copolymers, crosslinkers and biocide concentrations have been investigated. First, it can be seen that the addition of $7 \mathrm{wt} \%$ biocide has a strong influence on the loss of copolymer after 1 year in the rotor, for all the conditions studied, independently of the copolymer and crosslinker used. In addition, it can be seen that the choice of crosslinker does not have a significant effect on the loss of copolymer, both for biocide-free and biocide-containing coatings. Finally, the choice of copolymer seems to have a limited effect on the loss of copolymer, with the copolymer with lower $\mathrm{M}_{\mathrm{w}}$ (copolymer $\mathrm{B}$ ) showing higher loss as expected. Due to the similar behaviour of both copolymers, copolymer B was disregarded and copolymer $\mathrm{A}$ has been used for the remaining experiments. 


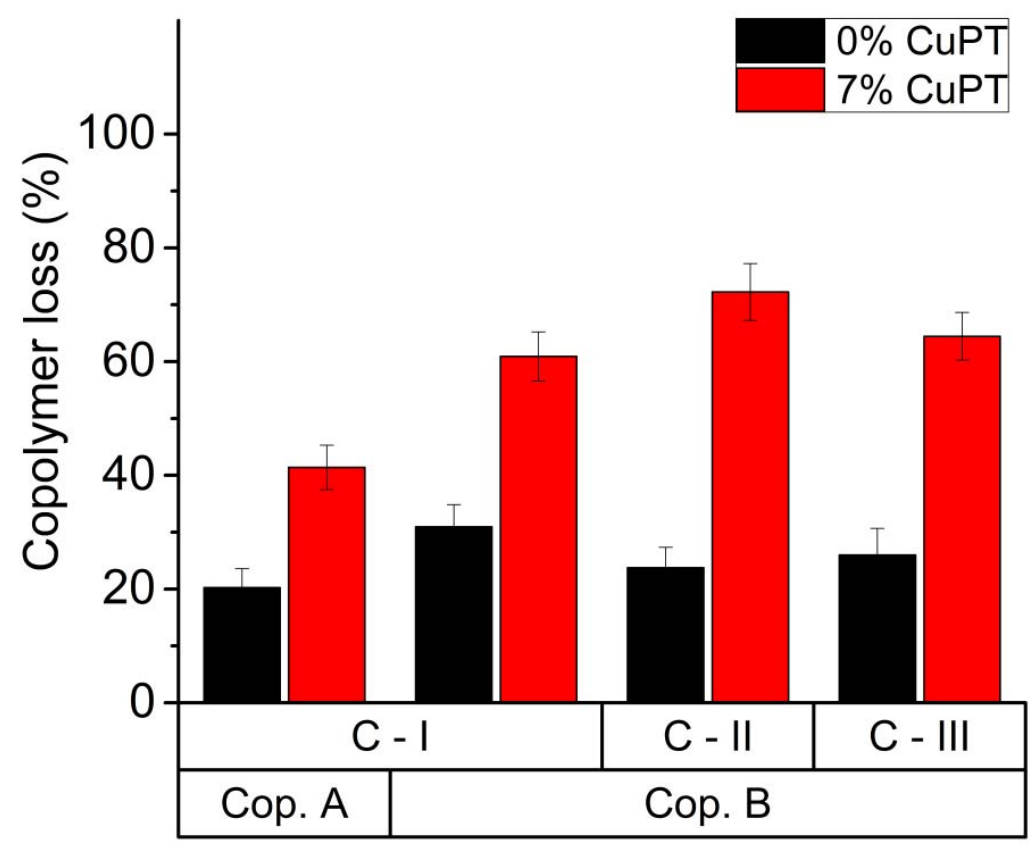

Figure 4. Copolymer loss (\%) for coatings with different compositions (copolymer, crosslinker and biocide concentration) containing initially $5 \mathrm{wt} \%$ of copolymer and exposed in the laboratory rotor $\left(25^{\circ} \mathrm{C}, 20\right.$ knots $)$ for 1 year. Series $\mathrm{A}$ in Table 2.

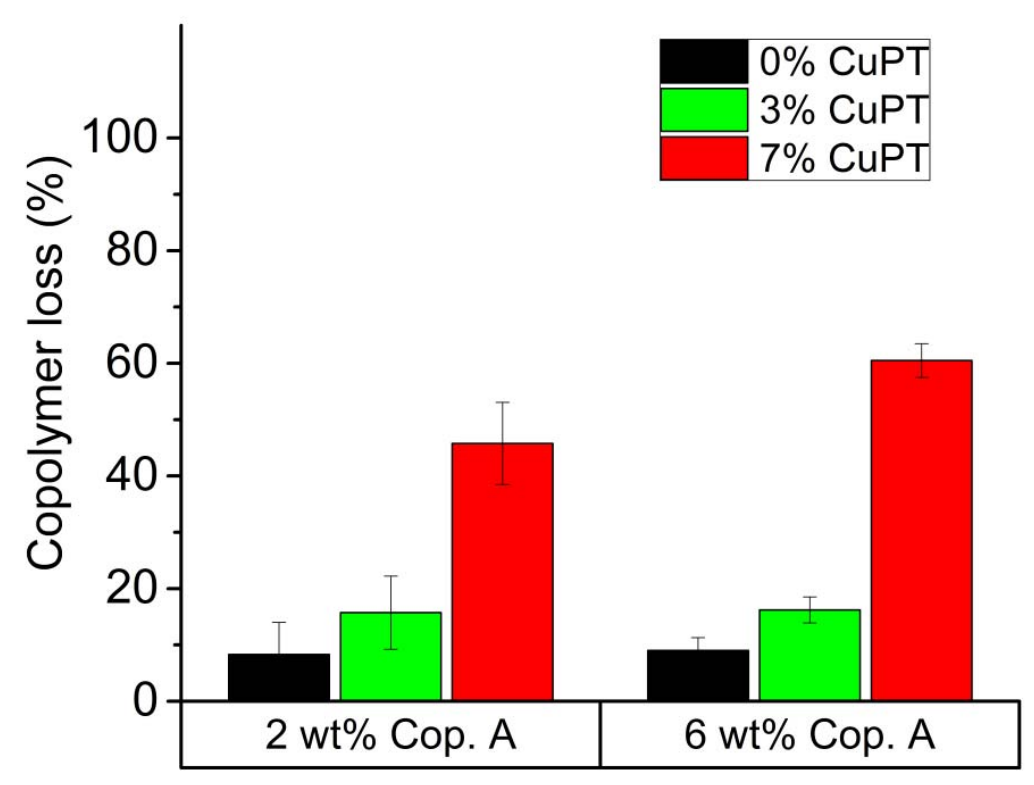

Figure 5. Copolymer A loss (\%) for coatings with different compositions (copolymer and biocide concentration) exposed in the laboratory rotor $\left(25^{\circ} \mathrm{C}, 20\right.$ knots) for 1 year. Series B in Table 2. 
Figure 5 shows the loss of copolymer from six different coatings (series B in Table 2). Similar to what has been shown in Figure 4, the initial concentration of CuPT in the coatings appears to have a strong influence on the results, with higher concentrations of biocide leading to greater losses of copolymer. Nonetheless, coatings with small concentrations of CuPT ( $3 \mathrm{wt} \%$ ) seem to behave more similarly to biocide free coatings after 1 year of exposure in the laboratory rotor than to those with high CuPT concentration (7 wt \%). As can be seen in Figure 5, coatings with $3 \mathrm{wt} \%$ CuPT show copolymer losses 1.5-2 fold compared to biocide free coatings, while coatings with 7 wt $\%$ CuPT exhibit losses 5-6 fold compared to biocide free coatings. The initial copolymer concentration in the coatings does not seem to have a significant effect on the loss of copolymer if the coatings with initially $2 \mathrm{wt} \%$ and $6 \mathrm{wt} \%$ of copolymer are compared (see Figure 5), although slight differences exist for the coatings with $7 \%$ CuPT.

\subsection{Static exposure experiments}

The results obtained from short-term (1 year) experiments in the laboratory rotor, presented in Figures 4 and 5 , are compared to coatings exposed to seawater in static conditions as previously detailed. Figure 6 shows the loss of copolymer from ten different coatings (series $C$ in Table 2) exposed for about 2 years in Singapore (Figure 6a) and Barcelona (Figure 6b) in static conditions, where the initial concentration of copolymer and biocide have been adjusted to different levels. These coatings possess comparable compositions to those in Figures 4 and 5 .

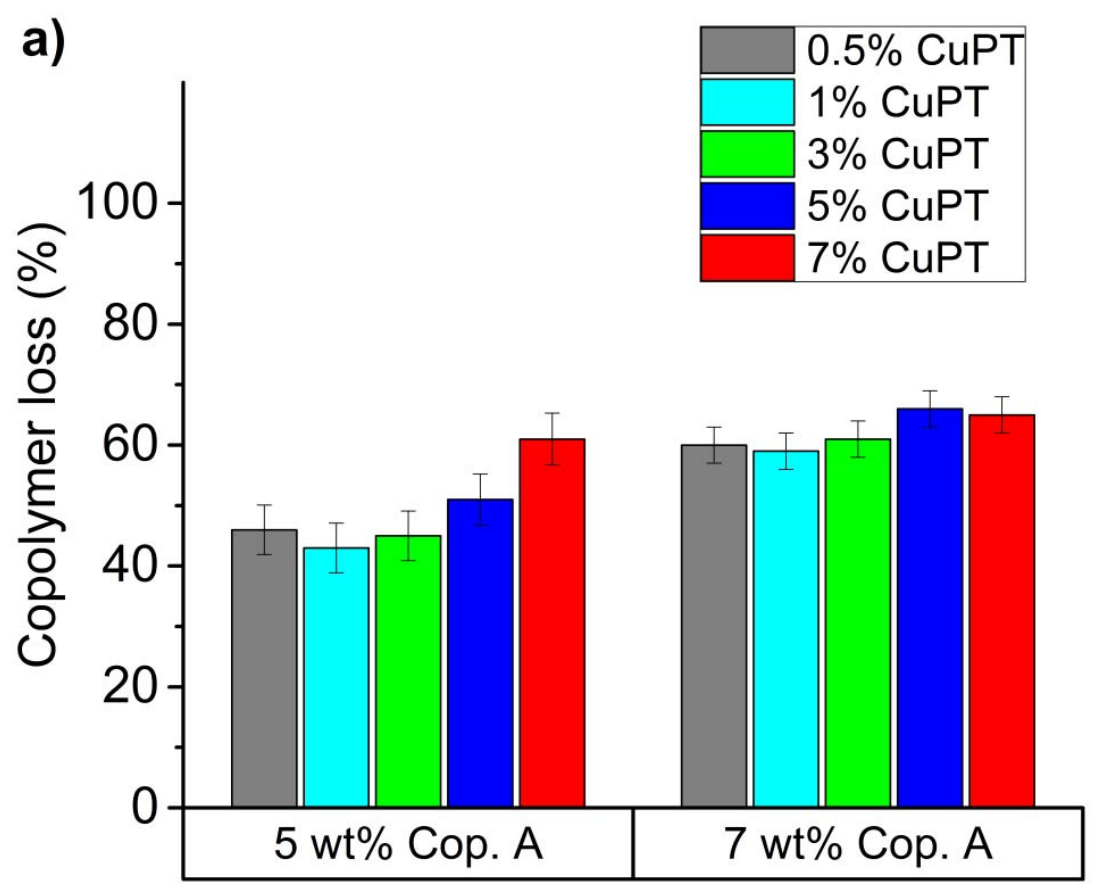




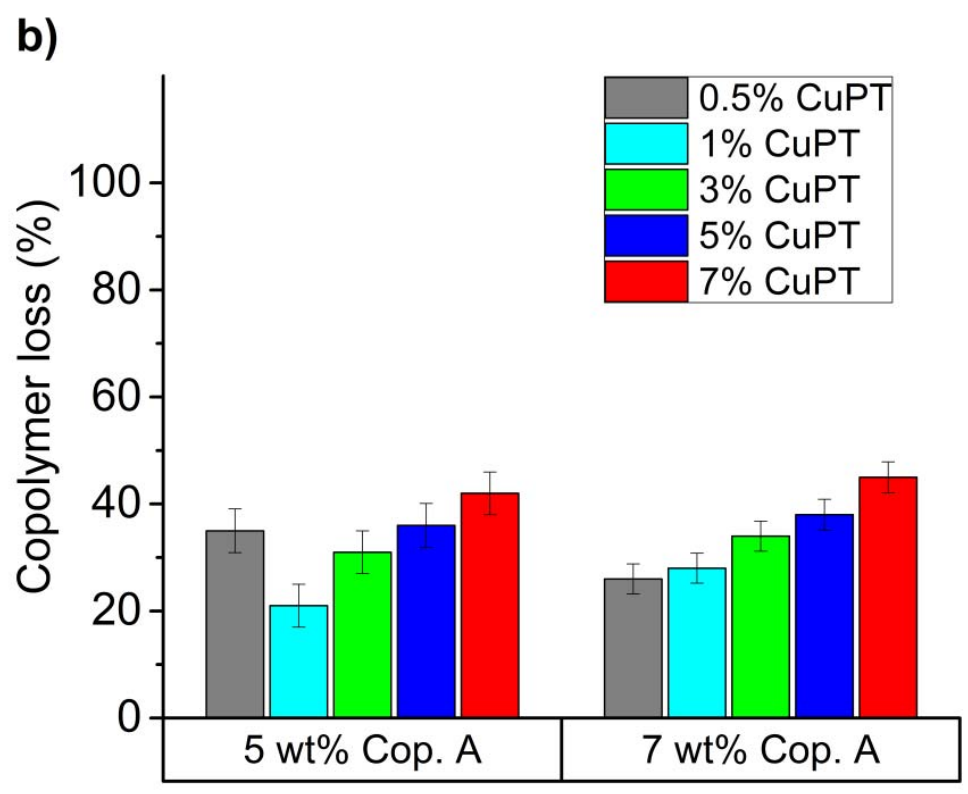

Figure 6. Copolymer A loss (\%) for ten coatings exposed for approximately 2 years in Singapore (a) and Barcelona (b), where different initial copolymer $A$ and biocide concentrations have been used. Series $C$ in Table 2.

It can be clearly seen that the loss of copolymer is distinctly higher in Singapore than in Barcelona when Figures $6 \mathrm{a}$ and $6 \mathrm{~b}$ are compared. Similar to Figure 5 , the initial concentration of copolymer in the coating does not seem to influence the copolymer loss, as evidenced by the fact that coatings containing $5 \mathrm{wt} \%$ and $7 \mathrm{wt} \%$ of copolymer suffer similar copolymer losses after 2 years of exposure. However, a clear difference can be seen between Figure 6 and Figures 4 and 5 regarding the impact of biocide concentration. Now, the initial concentration of CuPT has a little effect (if any) on the loss of copolymer for coatings statically exposed for 2 years in seawater, while it had a very important influence for coatings exposed 1 year in the laboratory rotor. This disagreement could be due to differences in exposure time (1 vs 2 years) or the distinctness regarding exposure conditions (dynamic vs static).

Finally, coatings with comparable compositions to those in Figure 6 have been exposed to long-term immersion in Singapore for 3.4 years and Barcelona for 5.2 years (series D in Table 2). After exposure, the loss of copolymer was evaluated and the results are plotted in Figure 7. 

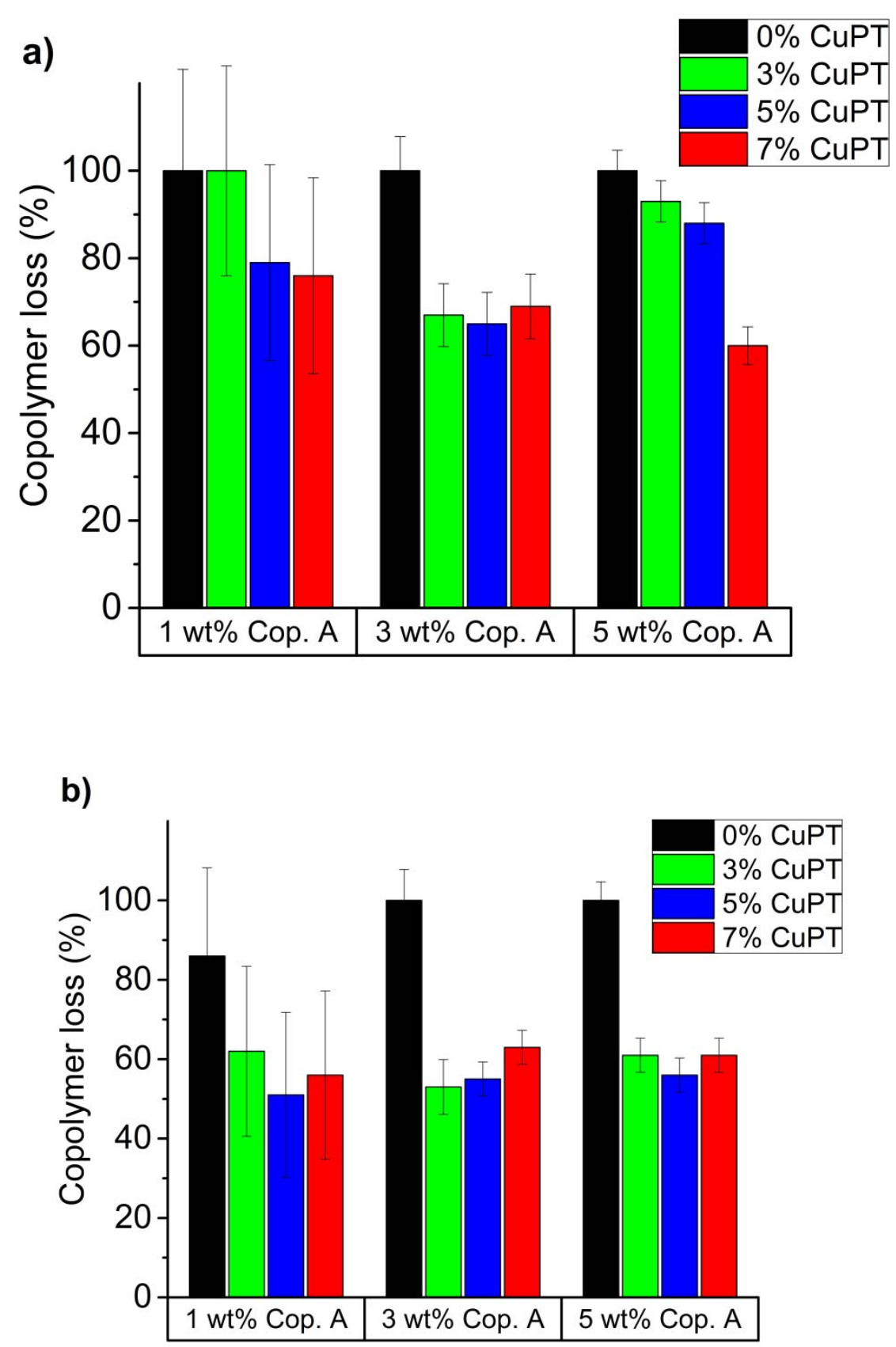

Figure 7. Copolymer A loss (\%) for twelve coatings exposed for 3.4 years in Singapore (a) and 5.2 years Barcelona (b), where different initial concentrations of copolymer $A$ and biocide have been used. Series D in Table 2.

Once more, the loss of copolymer is higher in Singapore compared to Barcelona. Moreover, the initial amount of copolymer in the coatings does not result in significant differences in its loss if coatings with $1 \mathrm{wt} \%, 3 \mathrm{wt} \%$ and $5 \mathrm{wt} \%$ in Figure 7 are compared (except for a few coatings exposed in Singapore containing low biocide concentrations, see Figure 7a). Nonetheless, the effect of the initial concentration of CuPT on the long-term loss of copolymer shows interesting results, with biocide-free coatings displaying (almost) total loss of copolymer, while biocide-containing coatings retaining 40 $50 \%$ of the initial copolymer (in BCN after 5.2 years) or $20-40 \%$ (in SNG after 3.4 years). This 
disagrees with the results in Figures 4 and 5, where after 1 year biocide-free coatings retained larger amounts of copolymer. It also contrasts with the results in Figure 6, where the concentration of biocide did not appear to influence the loss of copolymer for coatings exposed to seawater for 2 years.

\subsection{Effect of time}

Figures 4-7 have shown the copolymer loss from various coatings exposed in different conditions and some trends have been identified regarding the influence of seawater temperature and initial copolymer concentration. However, the effect of biocide concentration has displayed contradictory results depending on the exposure time, with higher CuPT concentrations leading to greater copolymer losses after 1 year exposure (see Figures 4 and 5), while showing higher copolymer retention in long-term experiments (see Figure 7). To investigate the effect of exposure time on the concentration of copolymer in PDMS coatings, two series of coatings ( $E$ and $F$ in Table 2) exposed to the laboratory rotor and seawater have been analysed. The copolymer concentration of these coatings have been analysed after different exposure times.

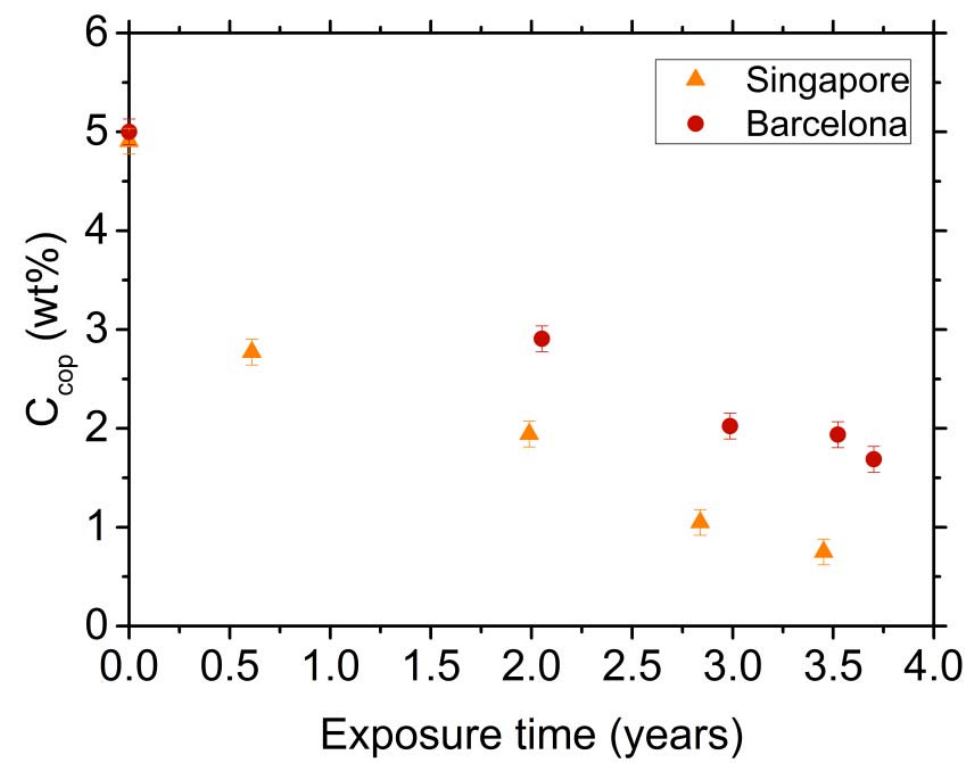

Figure 8. Copolymer A concentration (wt\%) in coatings exposed in Singapore (orange triangles) and Barcelona (red dots) for up to 3.7 years, initially containing $5 \mathrm{wt} \%$ of copolymer $\mathrm{A}$ and $7 \mathrm{wt} \%$ of biocide. Series $\mathrm{E}$ in Table 2. 


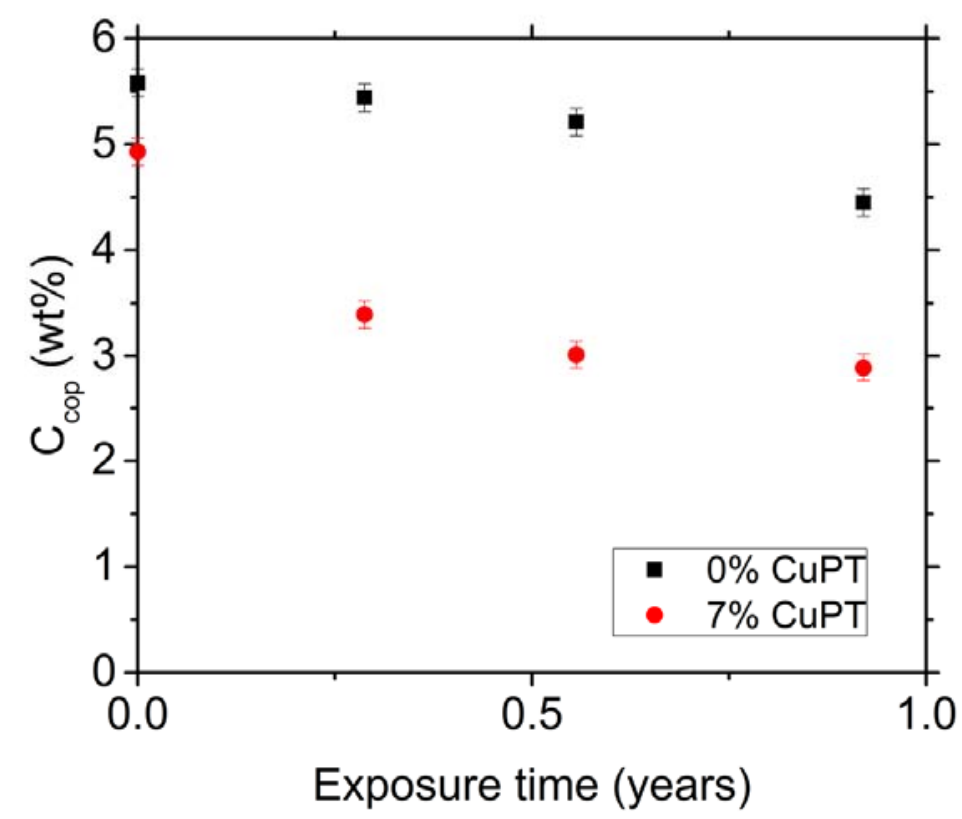

Figure 9. Copolymer $\mathrm{A}$ concentration (wt\%) in coatings exposed to the laboratory rotor $\left(25^{\circ} \mathrm{C}, 20\right.$ knots) for up to 1 year with different biocide concentration. Series $F$ in Table 2.

Figure 8 shows the concentration of copolymer in coatings exposed in Singapore for up to 3.7 years. These coatings contained initially $5 \mathrm{wt} \%$ of copolymer A and $7 \mathrm{wt} \%$ of CuPT. It appears that the release of copolymer is higher in the beginning and has a tendency to stabilize afterwards for these biocide-containing coatings in Singapore, while the loss is more or less constant in Barcelona. Again, higher copolymer losses are observed in Singapore than in Barcelona, as previously discussed.

Figure 9 shows the copolymer concentration over time in coatings exposed to the laboratory rotor for up to 1 year. It can be seen that the loss of copolymer is significantly higher for the biocide-containing coating, in agreement with Figure 4 and 5 . Moreover, different trends can be seen regarding copolymer concentration over time. The copolymer concentration in the CuPT-containing coating decreases more rapidly in the beginning, while the loss tends to stabilize, in agreement with Figure 8. Conversely, the loss of copolymer in the biocide-free coating appears to be very low in the beginning, though it suffers an important increase after the first half-year. These differences in release/loss trends could explain the (apparently) contradictory results previously presented. That is, if the tendencies presented in Figure 9 are extended to prolonged periods of time, it should be expected that: (1) the loss of copolymer is higher for biocide-containing coatings in short-term exposure, (2) somehow similar to biocide-free coatings in the mid-term and (3) significantly lower in the long-term. This assumption is consistent with the results presented in Figures 4-7. However, more experiments are required to confirm this hypothesis.

\subsection{Final remarks}

It is noteworthy that up to $40 \%$ of the initial copolymer concentration can be found in some coatings after 3.4 and 5.2 years of exposure in Singapore and Barcelona (see Figure 7). This indicates that the release of copolymer can be tuned by changing the composition of PDMS-based fouling-release 
coatings and can be used as a tool to better design fouling-release coatings with optimized properties. However, the copolymer chemical composition after immersion has not been studied. Hence, the copolymer retained in the coating can have suffered some changes in composition that might have suppressed its fouling-repellence properties or its surface-activity. However, in a previous study [33] the composition of PDMS-PEG-based copolymers retained in coatings after 2.5 years of exposure in Singapore was studied. In spite of some differences in composition compared to the original copolymer (mainly an increase in relative amount of PDMS), no traces of degradation products could be found in the coating. Moreover, both in those experiments and the ones presented here, the elution time of the copolymer in the SEC system remains completely stable, indicating that there is no change in molecular weight over time. This should not occur if the PEG block of the copolymer suffered oxidation, because the molecular weight of the copolymer would dramatically decrease and a shift in the chromatogram would be observed.

It has been additionally shown that the copolymer loss (expressed as \%, see Equation 2) is not dependent on the initial concentration of copolymer. Moreover, biocide-containing coatings show a higher loss of copolymer in the beginning, which tends to stabilize (see Figures 8 and 9). These two facts might be an indication that the copolymer concentration in the coating follows a first-order reaction rate law.

Note also that the effect of the release of CuPT or the presence of a leached layer have not been studied in this paper. Moreover, the release of biocides is dependent on the seawater temperature, which could be an important factor when biocide-containing coatings from Singapore and Barcelona are compared. Furthermore, the differences in copolymer loss between dynamic and static conditions have not been investigated. Differences between dynamic and static conditions are also expected to affect the release of biocide. Finally, the effect of the copolymer loss on the biofouling-inhibition properties of theses coatings has not been investigated and should be assessed in the future.

In spite of the differences and uncertainties mentioned, it can be clearly seen that valuable results can be acquired from experimental coatings exposed to a range of conditions. By preparing coatings with different compositions and analysing them after exposure, important results can be obtained, which can boost the development process of fouling-release coatings. Therefore, the development of analytical methods to understand and quantify the processes occurring in fouling-release coatings are believed to be a great tool towards the development of robust and long-lasting solutions. The analysis of coatings exposed to real seawater conditions can provide some insights that can largely outweigh the aforementioned uncertainties. In other words, results from field studies can evidence some aspects that are not available in short-term laboratory experiments. However, long waiting times are required to obtain real exposure conditions. Therefore, the development of reliable accelerated tests are still required to promote the research of fouling-release coatings.

\section{Conclusions}

In this field study, the release/loss of PDMS-PEG-based block copolymers from fouling-release coatings has been studied. Different variables such as the $M_{w}$ of the copolymer, the temperature of 
seawater or the initial CuPT concentration in the coating have been studied. To that purpose, a method to quantify the concentration of copolymer in PDMS coatings has been developed. Then, approximately 300 experimental coatings exposed to seawater in Singapore and Barcelona have been analysed. The results obtained from these coatings have been compared to coatings exposed in the laboratory rotor in controlled conditions.

The results have shown that the loss of copolymer from fouling-release coatings is strongly dependent on seawater temperature, with coatings exposed to Singapore showing greater losses than their homologues in Barcelona. Conversely, the initial copolymer concentration in the coating has no influence on the loss of copolymer for copolymer concentrations between 1 and $7 \mathrm{wt} \%$. In addition, the influence of CUPT concentration has been investigated. The results from seawater and rotary exposure suggest that the release of copolymer from biocide-containing and biocide-free coatings follow different profiles, with the former showing higher copolymer losses in the first immersion stages, while the latter displaying larger losses on long-term experiments. Finally, the molecular weight of the copolymer shows a limited influence on the release of copolymer from the coating, while the chemistry of the crosslinker does not have any significant effect.

In spite of some uncertainties, the strength of field studies has been proven regarding understanding some key phenomena occurring in fouling-release coatings such as the release of "oils". New insights can be brought by using real-exposure conditions when compared to traditional short-term laboratory experiments. The development of methods to analyse and quantify processes such as the release or degradation of additives in coatings are a great tool to complement traditional biofouling assays based on static exposure to seawater. Accelerated methods to investigate some of the aforementioned issues could enable a much faster development of robust fouling-release coatings in the future.

\section{Acknowledgements}

The financial support of the Danish Ministry for Science and Technology is gratefully acknowledged.

\section{References}

[1] M.A. Champ, A review of organotin regulatory strategies, pending actions, related costs and benefits, Sci. Total Environ. 258 (2000) 21-71. doi:10.1016/S0048-9697(00)00506-4.

[2] D.M. Yebra, S. Kiil, K. Dam-Johansen, Antifouling technology—past, present and future steps towards efficient and environmentally friendly antifouling coatings, Prog. Org. Coatings. 50 (2004) 75-104. doi:10.1016/j.porgcoat.2003.06.001.

[3] M. Lejars, A. Margaillan, C. Bressy, Fouling release coatings: A nontoxic alternative to biocidal antifouling coatings, Chem. Rev. 112 (2012) 4347-4390. doi:10.1021/cr200350v.

[4] R.E. Baier, Surface behaviour of biomaterials: The theta surface for biocompatibility, J. Mater. Sci. Mater. Med. 17 (2006) 1057-1062. doi:10.1007/s10856-006-0444-8.

[5] R.F. Brady, I.L. Singer, Mechanical factors favoring release from fouling release coatings, 
Biofouling. 15 (2000) 73-81. doi:10.1080/08927010009386299.

[6] J.K. Pike, T. Ho, K.J. Wynne, Water-induced surface rearrangements of poly (dimethylsiloxaneurea-urethane) segmented block copolymers, Chem. Mater. 8 (1996) 856-860. doi:10.1021/cm9504596.

[7] M.E. Callow, R.L. Fletcher, The influence of low surface energy materials on bioadhesion-a review, Int. Biodeterior. Biodegradation. 34 (1994) 333-348. doi:10.1016/0964-8305(94)900922.

[8] A.G. Nurioglu, A.C.C. Esteves, G. de With, Non-toxic, non-biocide-release antifouling coatings based on molecular structure design for marine applications, J. Mater. Chem. B. 3 (2015) 6547-6570. doi:10.1039/C5TB00232J.

[9] D.E. Wendt, G.L. Kowalke, J. Kim, I.L. Singer, Factors that influence elastomeric coating performance: the effect of coating thickness on basal plate morphology, growth and critical removal stress of the barnacle Balanus amphitrite, Biofouling. 22 (2006) 1-9. doi:10.1080/08927010500499563.

[10] B. Watermann, H. Berger, H. Sönnichsen, P. Willemsen, Performance and effectiveness of non-stick coatings in seawater, Biofouling. 11 (1997) 101-118. doi:10.1080/08927019709378323.

[11] J. Thomas, S.-B. Choi, R. Fjeldheim, P. Boudjouk, Silicones Containing Pendant Biocides for Antifouling Coatings, Biofouling. 20 (2004) 227-236. doi:10.1080/08927010400011229.

[12] C.J. Kavanagh, G.W. Swain, B.S. Kovach, J. Stein, C. Darkangelo-Wood, K. Truby, E. Holm, J. Montemarano, A. Meyer, D. Wiebe, The Effects of Silicone Fluid Additives and Silicone Elastomer Matrices on Barnacle Adhesion Strength, Biofouling. 19 (2003) 381-390. doi:10.1080/08927010310001623296.

[13] L. Cheng, Q. Liu, Y. Lei, Y. Lin, A. Zhang, The synthesis and characterization of carboxybetaine functionalized polysiloxanes for the preparation of anti-fouling surfaces, RSC Adv. 4 (2014) 54372-54381. doi:10.1039/C4RA09171J.

[14] D.R. Calabrese, B. Wenning, J.A. Finlay, M.E. Callow, J.A. Callow, D. Fischer, C.K. Ober, Amphiphilic oligopeptides grafted to PDMS-based diblock copolymers for use in antifouling and fouling release coatings, Polym. Adv. Technol. 26 (2015) 829-836. doi:10.1002/pat.3515.

[15] J.J. Stein, K. Truby, C.D. Wood, J.J. Stein, M. Gardner, G. Swain, C. Kavanagh, B. Kovach, M. Schultz, D. Wiebe, E. Holm, J. Montemarano, D. Wendt, C. Smith, A. Meyer, Silicone foul release coatings: effect of the interaction of oil and coating functionalities on the magnitude of macrofouling attachment strengths., Biofouling. 19 Suppl (2003) 71-82.

doi:10.1080/0892701031000089525. 
[16] H. Lee, L.A. Archer, Functionalizing polymer surfaces by surface migration of copolymer additives: role of additive molecular weight, Polymer. 43 (2002) 2721-2728.

doi:10.1016/S0032-3861(02)00041-1.

[17] A. Camós Noguer, S.M. Olsen, S. Hvilsted, S. Kiil, Diffusion of surface-active amphiphiles in silicone-based fouling-release coatings, Prog. Org. Coatings. 106 (2017) 77-86. doi:10.1016/j.porgcoat.2017.02.014.

[18] E. Berndt, S. Behnke, A. Dannehl, A. Gajda, J. Wingender, M. Ulbricht, Functional coatings for anti-biofouling applications by surface segregation of block copolymer additives, Polymer 51 (2010) 5910-5920. doi:10.1016/j.polymer.2010.10.002.

[19] T. Miyata, Y. Nakanishi, T. Uragami, Ethanol Permselectivity of Poly(dimethylsiloxane) Membranes Controlled by Simple Surface Modifications Using Polymer Additives, Macromolecules. 30 (1997) 5563-5565. doi:10.1021/ma9618843.

[20] M. Inutsuka, N.L. Yamada, K. Ito, H. Yokoyama, High density polymer brush spontaneously formed by the segregation of amphiphilic diblock copolymers to the polymer/water interface, ACS Macro Lett. 2 (2013) 265-268. doi:10.1021/mz300669q.

[21] A.P. Narrainen, L.R. Hutchings, I. Ansari, R.L. Thompson, N. Clarke, Multi-End-Functionalized Polymers: Additives to Modify Polymer Properties at Surfaces and Interfaces, Macromolecules. 40 (2007) 1969-1980. doi:10.1021/ma062349y.

[22] J. Seo, L.P. Lee, Effects on wettability by surfactant accumulation/depletion in bulk polydimethylsiloxane (PDMS), Sensors Actuators, B Chem. 119 (2006) 192-198. doi:10.1016/j.snb.2005.12.019.

[23] H.T. Kim, J.K. Kim, O.C. Jeong, Hydrophilicity of surfactant-added poly(dimethylsiloxane) and its applications, Jpn. J. Appl. Phys. 50 (2011). doi:10.1143/JJAP.50.06GL04.

[24] C.H. Loh, R. Wang, Insight into the role of amphiphilic pluronic block copolymer as poreforming additive in PVDF membrane formation, J. Memb. Sci. 446 (2013) 492-503. doi:10.1016/j.memsci.2013.07.016.

[25] H. Susanto, M. Ulbricht, Characteristics, performance and stability of polyethersulfone ultrafiltration membranes prepared by phase separation method using different macromolecular additives, J. Memb. Sci. 327 (2009) 125-135. doi:10.1016/j.memsci.2008.11.025.

[26] H. Madadi, J. Casals-Terré, Long-term behavior of nonionic surfactant-added PDMS for selfdriven microchips, Microsyst. Technol. 19 (2013) 143-150. doi:10.1007/s00542-012-1641-7.

[27] A. Fatona, Y. Chen, M. Reid, M.A. Brook, J.M. Moran-Mirabal, One-step in-mould modification of PDMS surfaces and its application in the fabrication of self-driven microfluidic channels, Lab Chip. 15 (2015) 4322-4330. doi:10.1039/C5LC00741K. 
[28] P.C.W. Thorlaksen, Fouling control coating compositions comprising polysiloxane and pendant hydrophilic oligomer/polymer moieties, WO2013000478, 2013.

[29] S. Tanino, Antifouling coating composition, antifouling coating film, antifouling substrate, and method for improving storage stability of antifouling coating compositions, US2015299515, 2015.

[30] A. Reynier, P. Dole, S. Humbel, A. Feigenbaum, Diffusion coefficients of additives in polymers. I. Correlation with geometric parameters, J. Appl. Polym. Sci. 82 (2001) 2422-2433. doi:10.1002/app.2093.

[31] S. Kiil, C.E. Weinell, M.S. Pedersen, K. Dam-Johansen, Analysis of self-polishing antifouling paints using rotary experiments and mathematical modeling, Ind. Eng. Chem. Res. 40 (2001) 3906-3920. doi:10.1021/ie010242n.

[32] Anonymous, A Summary of Error Propagation, 2007. http://ipl.physics.harvard.edu.

[33] A. Camós Noguer, S.M. Olsen, S. Hvilsted, S. Kiil, Long-term stability of PEG-based antifouling surfaces in seawater, J. Coatings Technol. Res. 13 (2016) 567-575. doi:10.1007/s11998-0169801-9. 